\title{
Vegetación de humedales en áreas de turismo de aventura en la zona Maya de México
}

\author{
Wetland vegetation in areas of adventure tourism in the \\ Mayan zone of Mexico
}

\author{
Héctor Cálix de Dios*
}

\begin{abstract}
Resumen
Objetivo: Conocer los tipos de vegetación y la flora de lagunas con un gran potencial de turismo de aventura, y con vegetación y fauna, bastante conservadas. Metodología: En El Creek (en el extremo norte de la Laguna de Bacalar), en Laguna Guerrero, y en Laguna Chile Verde, entre 2011 y 2012, se realizaron tres recorridos en cada una (dos en lancha de motor y uno a pie, por la ribera de los cuerpos de agua), se colectaron las especies vegetales, se tomaron los datos de las características ecológicas de los sitios; se identificaron las especies en los herbarios de la localidad, se identificaron los tipos de vegetación y se realizó el análisis de la información. Resultados: se encontraron siete tipos de vegetación asociados con los cuerpos de agua y más de 50 especies, entre hierbas, arbustos y árboles; se destaca la importancia ecológica y turística de esta información. Conclusión: La vegetación hidrófita del sitio de estudio, se mantiene todavía poco alterada, porque son áreas sujetas a inundación, poco aptas para el desarrollo de actividades productivas, sin embargo, es necesario plantear un programa de conservación que ayude a mantener ese estado y por lo tanto, se privilegie la zona conservada y pueda tener un uso ecoturístico de bajo impacto.
\end{abstract}

Palabras clave: Conservación, Flora, Lagunas, Vegetación.

\begin{abstract}
Objective: To identify the types of vegetation and flora in three lagoons that show great promise as sites for alternative, while simultaneously offering ample opportunity for ecological preservation. Methods: the study was undertaken between 2011 and 2012, in Guerrero Lagoon, Chile Verde Lagoon, and EI Creek (which is the extreme north of Bacalar Lagoon, where field trips by boat and walking along the river bank field trips, were carried out; plant species were collected and ecological data were recorded. Species were identified in the regional herbaria, type of vegetation were identified, and information were analyzed. Results: this study has documented the presence of seven types of vegetation in and near the water bodies and more than 50 plant species including small plants, bushes, and trees, and the importance of ecological and tourist information is highlighted. Conclusions: The hydrophytic vegetation of the sites, is still conservated, because they are areas subject to flooding, and then they are unsuitable for the development of productive activities; however, it is necessary to start a conservation program in order to keep the conservation state and therefore, this area could preserved and may be useful to a low impact ecotourism use.
\end{abstract}

Keywords: Conservation, Flora, Lagoons, Vegetation.

\section{Introducción}

La fuente más importante de ingreso en la Zona Maya de México (en la Península de Yucatán), la constituye el turismo; específicamente, las playas, las ruinas arqueológicas, y muy lejanamente, los museos. Sin embargo, durante los últimos años, se ha empezado a abrir otra modalidad de turismo que ha cobrado interés en la Zona Maya: el turismo de aventura. En la península de Yucatán, la mayoría de los cuer-

* Carrera de Agroecología, Departamento de Desarrollo Sostenible, Universidad Intercultural Maya de Quintana Roo (UIMQROO), estado de Quintana Roo, México. e-mail: hector.calix@uimqroo.edu.mx

Fecha recepción: Octubre 22, $2013 \quad$ Fecha aprobación: Febrero 22, 2014 Editor asociado: Quinto H 
pos de agua están en forma de «cenotes», las corrientes superficiales (varias lagunas y muy pocos ríos), son escasas, y están cercanas a las costas. De tal manera que es entorno a las lagunas, que se han venido constituyendo cooperativas de turismo de aventura; sin embargo, es poco el conocimiento que se tiene sobre las características biológicas de estos sitios, conocimiento que es muy importante, tanto para la información que recibe el turista, como para plantear los programas de conservación de estas zonas.

Con base en ello, nos propusimos realizar un inventario florístico de las principales lagunas que apenas inician con trabajos de turismo de aventura en la Zona Maya de la Península de Yucatán, en México y conocer sus tipos de vegetación.

\section{Metodología}

Área de estudio. La presente investigación se realizó entre 2011 y 2012, en las tres lagunas: El Creek, una especie de río que se localiza en la punta norte de la Laguna de Bacalar; la «Laguna Guerrero» y la «Laguna Chile Verde» (Figura 1). De acuerdo con SEMARNAT (2011), «el clima donde se ubica el si- tio de estudio es sub-húmedo y muy cálido, con época de lluvias en verano. La temperatura promedio anual es de $27^{\circ} \mathrm{C}$, con temperatura máxima de $40^{\circ} \mathrm{C}$ y mínima de $14^{\circ} \mathrm{C}$ y precipitación promedio anual de $1.249 \mathrm{~mm}$. Esta región tiene ingreso de humedad proveniente del mar Caribe, siendo el mes de julio el de mayor humedad relativa con $93 \%$ y marzo con la menor de 80,9\%». En los tres sitios, el aprovechamiento de los recursos naturales, se da básicamente sobre las palmáceas (tanto para la construcción de casas tradicionales, como para la venta en la zona turística de Cancún); la extracción de bajareques (árboles con un DAP menor a $10 \mathrm{~cm}$ ) para conformar las paredes de las viviendas tradicionales; la pesca menor (mojarras de menos de $200 \mathrm{~g}$ ), la cacería de aves y pequeños mamíferos; la agricultura (piña, maíz, fríjol, calabaza, papaya, pitahaya); la explotación forestal (cedro y caoba, en muy pequeños volúmenes); la ganadería incipiente (ganaderos con un máximo de 10 cabezas de ganado); y recientemente el turismo de aventura; de hecho, en la comunidad de Raudales, donde está la Laguna Guerrero, existe un Comité de Turismo, cuya organización y objetivos están encaminados a la conservación y protección del me-

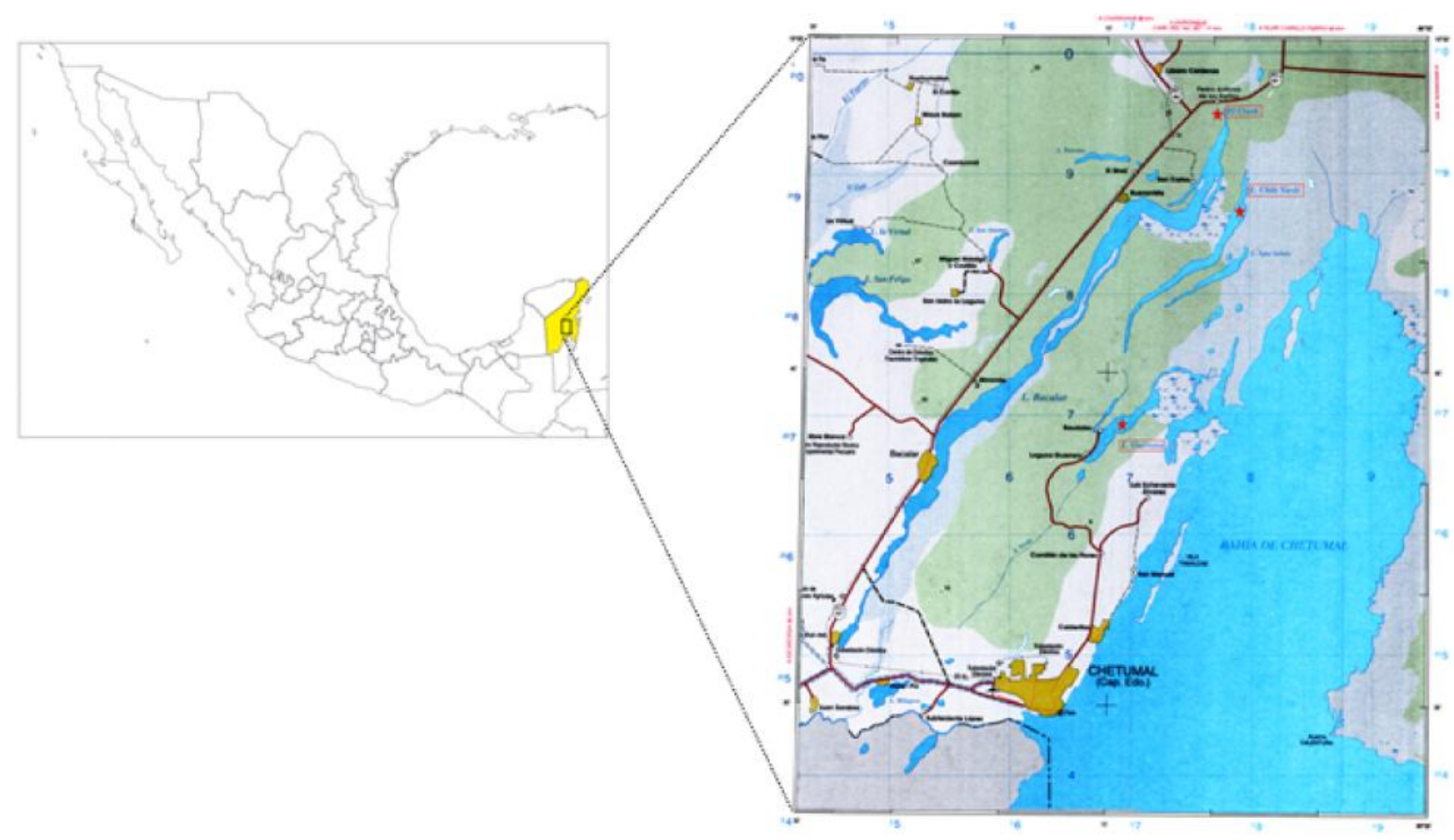

Figura 1. Mapa de la república mexicana, indicando la localización del sitio de estudio (con los cuerpos de agua, señalados con estrellas). 
dio ambiente ante la posibilidad del desarrollo de la actividad turística en la localidad (Cortina y Silva 2000).

Laguna El Creek. El área de estudio está entre $18^{\circ} 45^{\prime}$ y $19^{\circ} 00^{\prime}$ norte y $88^{\circ} 05^{\prime}$ y $88^{\circ} 20$ oeste; se encuentra a una altitud promedio de cinco metros. La Laguna de Bacalar se extiende desde la población de Xul-Ha, continúa casi paralela a la carretera federal, pasando por las comunidades de Bacalar y Buenavista, y termina en el poblado de Pedro Antonio de los Santos. A la altura de este último, es donde la Laguna de Bacalar finaliza ensanchando sus márgenes, hasta culminar en una especie de riachuelo corto, que los pobladores de esa localidad, conocen como El Creek. Este cuerpo de agua, tiene una longitud aproximada de $1 \mathrm{~km}$, desde la entrada hasta su recodo final y su anchura varía entre 20 y 100 m aproximadamente; en esta parte, por la naturaleza de la formación del cuerpo de agua, se generan solamente corrientes lénticas, lo que favorece el crecimiento de formas de vida particulares como la de vegetación acuática estricta (Figura 2).

Laguna Guerrero. Esta localidad, se encuentra en el municipio de Othón P. Blanco (en el estado de Quintana Roo). La laguna está situada entre $18^{\circ} 41^{\prime}$ y $18^{\circ} 45^{\prime}$ norte y $88^{\circ} 09^{\prime}$ y $88^{\circ} 16^{\prime}$ oeste; se encuentra a una altitud promedio de $10 \mathrm{~m}$. La mayoría del área de esta zona está sobre suelos akalché (arcilloso pesado), con poco drenaje y áreas inundables, lo que se traduce en palmares, manglares, vegetación arbórea en bajos inundables, vegetación en bajos inundables (básicamente pastizales) y vegetación arbórea en la zona continental (Figura 3).

Laguna Chile Verde. Está localizada en el mu-

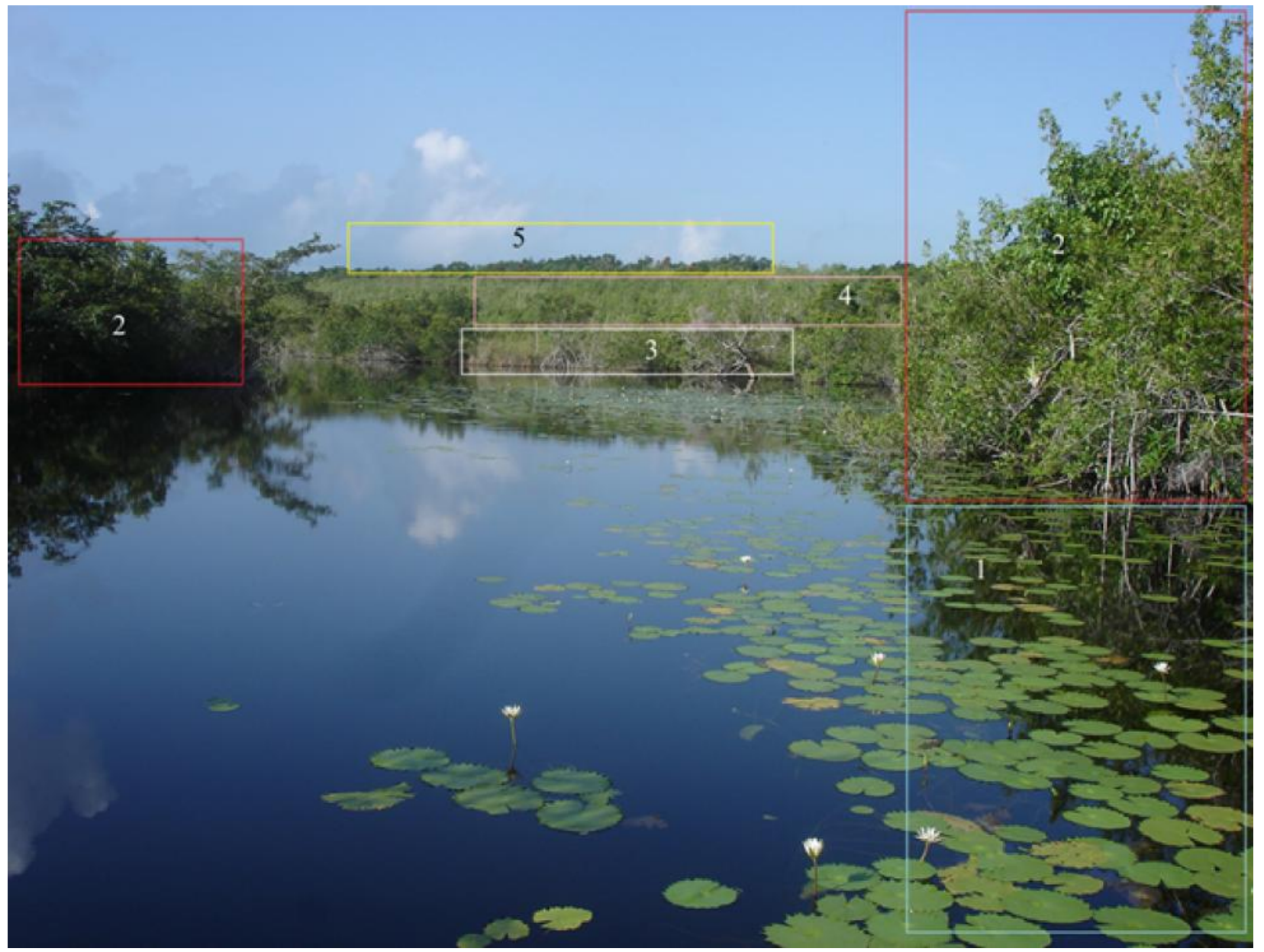

Figura 2. Imagen de la vegetación de El Creek, presentando los tipos de vegetación: 1) vegetación acuática estricta; 2) vegetación de manglar; 3) vegetación subacuática; 4) vegetación arbórea en bajos inundables; y 5) Vegetación arbórea baja. 


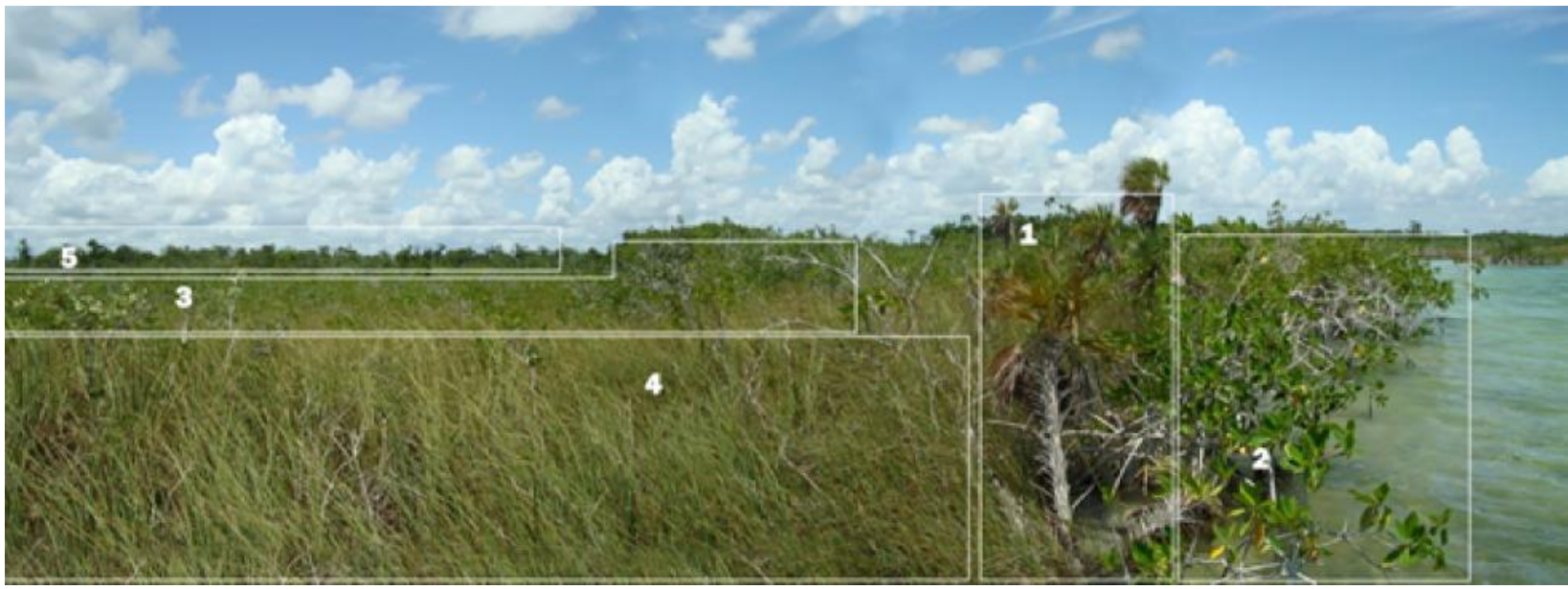

Figura 3. Imagen de la vegetación de Laguna Guerrero, presentando los tipos de vegetación: 1) palmares 2) vegetación de manglar; 3) vegetación arbórea en bajos inundables; 4) vegetación en bajos inundables (pastos); y 5) Vegetación arbórea en la zona continental.

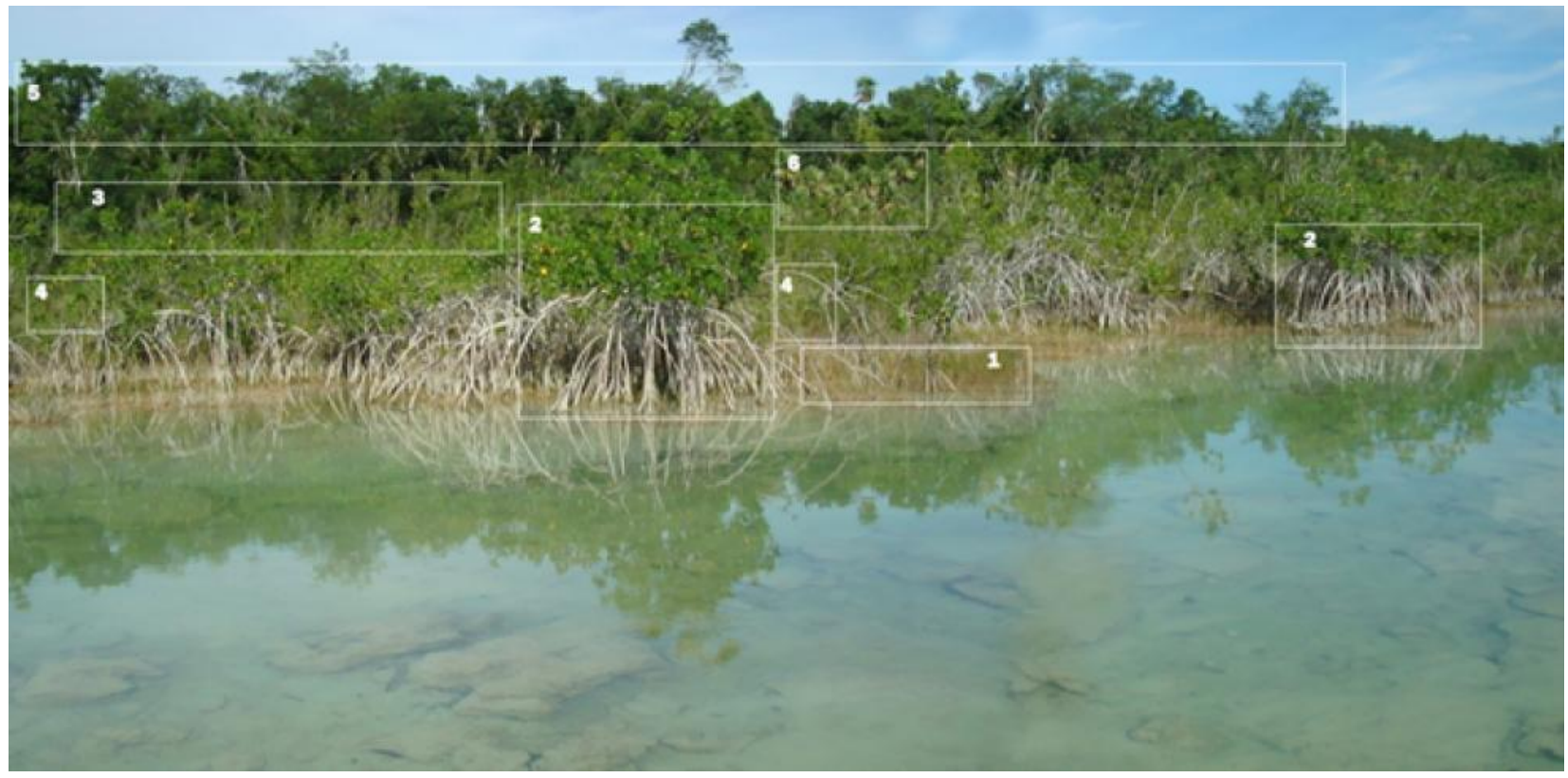

Figura 4. Imagen de la vegetación de Laguna Chile Verde, presentando los tipos de vegetación: 1) vegetación subacuática (ciperáceas) 2) vegetación de manglar; 3) vegetación de galería; 4) vegetación en bajos inundables (pastos); 5) Vegetación arbórea (elementos de selva mediana); y 6) palmares.

nicipio de Othón P. Blanco (estado de Quintana Roo) entre $18^{\circ} 46^{\prime}$ y $18^{\circ} 54^{\prime}$ norte y $88^{\circ} 08^{\prime}$ y $88^{\circ} 14^{\prime}$ oeste y está a una altitud promedio de ocho metros. La mayor parte del suelo de este sitio, está constituido por áreas inundables, es decir, vegetación subacuática, manglares, vegetación de galería, bajos inundables (pastos), palmares y vegetación arbórea, básicamente elementos de selva mediana (Figura 4).

Métodos. Se realizaron tres recorridos en cada laguna (dos en lancha de motor y uno a pie, por la ribera de los cuerpos de agua) con el fin de colectar las especies vegetales y tomar datos de las características ecológicas de los sitios. La identificación taxonómica del material vegetal recolectado se realizó en los herbarios de la localidad, específicamente en el Herbario ECO-CH-H, de la Unidad Chetumal de El Colegio de la Frontera Sur (ECOSUR), en Quintana Roo, México y en el herbario CICY, de la Unidad de Recursos Naturales, del Centro de Investigación Científica de Yucatán, AC (CICY), en 
Yucatán, México. Adicionalmente, se usaron claves taxonómicas (Waters y Kimberley 2007, Murrell 2010, Grantley et al. 2009, Rizzo y Boser 2009, Enquist y Sullivan 2001, VLMP 2001, Cabrera et al. 1982). Para identificar, clasificar y describir los tipos de vegetación en el sitio de estudio, se consultó a Leopold (1950), Miranda (1959), Miranda y Hernández (1963), Rzedowski (1978), y Vester y Calmé (2003). Los ejemplares quedaron depositados en el Herbario de la Universidad Intercultural Maya de Quintana Roo (en formación).

\section{Resultados}

Encontramos más de 50 especies (Tabla 1), entre mangles, pastos, epífitas, árboles y arbustos, y al menos siete tipos diferentes de vegetación (vegetación acuática estricta, vegetación de manglar, vegetación subacuática, vegetación arbórea en bajos inundables, vegetación arbórea baja, petenes y selva baja subcaducifolia).

Vegetación de El Creek. Los tipos de vegetación que se encuentran en El Creek (Figura 2, Tabla 1) son los siguientes: 1) vegetación acuática estricta, con asociación de ninfa o flor de agua (Nymphaea ampla) y asociación de pasto aguja (Eleocharis cellulosa); 2)manglar, con vegetación de galería con predominancia de mangle rojo (Rhizophora mangle) y vegetación de galería con predominancia de mangle botoncillo (Conocarpus erectus) y mangle blanco (Laguncularia racemosa); 3) vegetación subacuática, con asociación predominante de cortadera Cladium jamaicense y otras hierbas como Rhynchospora colorata, Viguiera dentata, chilillo (Lisianthus axilaris), asociación de zacate «ch'it suuk» o cola de venado (Andropogon glomeratus) y otras hierbas, y saibal-manglar con «cortadera» $(C$. jamaicense), mangle botoncillo (C. erectus) y palma tasiste (Acoelorhaphe wrightii) y otras hierbas asociadas como Bletia purpurea, Panicum maximun, Cassytha filiformis y algunos individuos de Coccoloba reflexiflora; 4) vegetación arbórea en bajos inundables, con selva baja inundable con pukté (Bucida buceras) y Croton reflexifolius y 5) vegetación arbórea baja, con selva baja subcaducifolia con palma de chit (Thrinax radiata), yaaxnik (Vitex gaumeri) y chicozapote (Manilkara zapota).

Vegetación de Laguna Guerrero y Laguna
Chile Verde. En las lagunas Guerrero y Chile Verde, la mayor parte de la vegetación (Figuras 3 y 4, Tabla 1) que se encuentra en la ribera, es manglar, aunque también hay zacates (Poaceae) y ciperáceas, además de las epífitas asociadas con el mangle; también hay plantas acuáticas estrictas aunque son muy pocas, solo algunas ciperáceas (E. cellulosa) predominando la vegetación subacuática, la vegetación de galería, la vegetación riparia, y la vegetación de zonas inundables, tomando en cuenta la dirección desde el centro del cuerpo de agua, hacia la zona continental.

En Laguna Guerrero y Laguna Chile Verde, debido a su riqueza específica, sus zonas de vegetación continental forman parte de las áreas con uso productivo de los ejidos vinculados con estos cuerpos de agua. En esta zona existen remanentes de selva mediana subperennifolia con palmas y una gran cantidad de hierbas y arbustos en la orilla de las lagunas, además de muchas epífitas ligadas con las asociaciones de mangle y pukté (Bucida buceras), tanto en la zona continental como en los islotes que se pueden observar en ambas lagunas. En términos generales y probablemente por lo inaccesible de la zona, en su conjunto, la vegetación de esta área tiene un alto grado de conservación, porque las asociaciones vegetales presentan comunidades cerradas, individuos entre 10 y $15 \mathrm{~m}$ de altura (sobre todo hacia la zona continental), y hasta cierto punto se conserva la estructura horizontal y vertical de la vegetación.

\section{Detalle de la vegetación en las tres zonas inundables}

1. Vegetación acuática estricta. Se entiende como vegetación acuática estricta la que está en áreas que presentan una inundación permanente (Ramos y Novelo 1993, Cálix de Dios et al. 1996). A pesar de que esta vegetación es muy limitada en los cuerpos de agua dulce, y está en grupos aislados a lo largo de la Laguna de Bacalar, casi a lo largo de todo El Creek, hay dos asociaciones vegetales: la asociación de ninfa o flor de agua (N. ampla), y la asociación de pasto aguja (E. cellulosa). La vegetación acuática estricta prevalece casi a lo largo de todo El Creek y hay solamente dos especies, $N$. ampla y E. cellulosa. La ninfa está sobre todo hacia el centro de El Creek (Figura 2), aunque en ocasiones es bastante abun- 
Tabla 1. Ubicación de las especies en los cuerpos de agua.

\begin{tabular}{|c|c|c|c|c|c|c|}
\hline \multirow{2}{*}{$\begin{array}{c}\text { Familia } \\
\text { Acanthaceae }\end{array}$} & \multirow{2}{*}{$\begin{array}{c}\text { Especie } \\
\text { Bravaisia tubiflora Hemsl. }\end{array}$} & \multirow{2}{*}{$\begin{array}{l}\begin{array}{l}\text { Nombre } \\
\text { común }\end{array} \\
\text { Sulub }\end{array}$} & \multirow{2}{*}{$\begin{array}{c}\begin{array}{c}\text { Forma de } \\
\text { vida }\end{array} \\
\text { Arbusto }\end{array}$} & \multicolumn{3}{|c|}{$\begin{array}{l}\text { Cuerpos de agua donde } \\
\text { está presente la especie }\end{array}$} \\
\hline & & & & EC & LG & LChV \\
\hline Apocynaceae & Rhabdadenia biflora (Jacq.) Müll. Arg. & Flor de mangle & Trepadora & EC & LG & LChV \\
\hline \multirow{2}{*}{ Arecaceae } & $\begin{array}{l}\text { Metopium brownei (Jacq.) Urb. } \\
\text { Acoelorraphe wrightii Griseb. \& H. }\end{array}$ & Chechem & Árbol & EC & LG & LChV \\
\hline & $\begin{array}{l}\text { Wendl. ex Becc. } \\
\text { Thrinax radiata Lood. ex Schult.\& }\end{array}$ & Tasiste & Palma & EC & LG & LChV \\
\hline Arecaceae & Schult. f. & Chit & Árbol & EC & LG & LChV \\
\hline Bromeliaceae & Tillandsia bulbosa Hook. & neh ku'uk & Epífita & EC & LG & LChV \\
\hline \multirow[t]{2}{*}{$\begin{array}{l}\text { Bromeliaceae } \\
\text { Bromeliaceae }\end{array}$} & $\begin{array}{l}\text { Tillandsia dasyliirifolia Baker } \\
\text { Tillandsia streptophylla Scheidw. Ex }\end{array}$ & -- & Epífita & EC & LG & LChV \\
\hline & C. Morren & -- & Epífita & EC & LG & LChV \\
\hline Burseraceae & Bursera simaruba (L.) Sarg. & Chaká & Árbol & EC & LG & LChV \\
\hline Combretaceae & Bucida buceras L. & Pucte & Árbol & EC & LG & LChV \\
\hline Combretaceae & $\begin{array}{l}\text { Conocarpus erectus } \mathrm{L} \text {. } \\
\text { botoncillo }\end{array}$ & $\begin{array}{l}\text { Mangle } \\
\text { Árbol }\end{array}$ & $\mathrm{EC}$ & LG & LChV & \\
\hline \multirow[t]{2}{*}{ Combretaceae } & Laguncularia racemosa (L.) & & & & & \\
\hline & C. F. Gaertn. & Mangle blanco & Árbol & EC & LG & LChV \\
\hline \multirow{2}{*}{$\begin{array}{l}\text { Cyperaceae } \\
\text { Cyperaceae }\end{array}$} & Eleocharis cellulosa Torr. & Pasto aguja & Herbácea & EC & LG & LChV \\
\hline & Cladium jamaicense C.B. Clarke & $\begin{array}{l}\text { Cortadera o } \\
\text { Saibal }\end{array}$ & Herbácea & EC & LG & \\
\hline Cyperaceae & Fimbristylis cymosa R. Br. & -- & Herbácea & $\mathrm{EC}$ & LG & LChV \\
\hline Fabaceae & Lysiloma latisiliquum (L.) Benth. & Tzalam & Arbol & EC & LG & LChV \\
\hline Fabaceae & Piscidia piscipula (L.) Sarg. & Habin & Árbol & $\mathrm{EC}$ & LG & LChV \\
\hline Fabaceae & Dalbergia glabra (Mill.) Standl. & Kibix & Arbusto & EC & LG & LChV \\
\hline Lauraceae & Cassytha filiformis $\mathrm{L}$. & Fideo & Parásita & EC & LG & LChV \\
\hline Loranthaceae & Psittacanthus calyculatus (DC) G. Don & Matapalo & Parásita & EC & LG & LChV \\
\hline Malvaceae & Hampea trilobata Standl. & Majahua & Arbusto & EC & LG & LChV \\
\hline Orchidaceae & Oncidium ascendens Lindl. & Orquídea & Epífita & EC & LG & LChV \\
\hline \multirow[t]{2}{*}{ Poaceae } & Andropogon glomeratus (Walter) & & & & & \\
\hline & Britton, Sterns \& Poggenb. & ch'it suuk & Hierba & $\mathrm{EC}$ & LG & LChV \\
\hline Polygonaceae & Coccoloba diversifolia Jacq. & Saklop & Árbol & EC & LG & LChV \\
\hline Rhamnaceae & Randia aculeata $\mathrm{L}$. & -- & Arbusto & $\mathrm{EC}$ & LG & LChV \\
\hline Rhizophoraceae & Rhizophora mangle $\mathrm{L}$. & Mangle rojo & Arbol & EC & LG & LChV \\
\hline Sapotaceae & Manilkara zapota (L.) P. Royen & Chicozapote & Árbol & EC & LG & LChV \\
\hline Annonaceae & Annona glabra L. & Anonillo & Árbol & & LG & LChV \\
\hline Arecaceae & Cocos nucifera $\mathrm{L}$. & Coco & Palma & & LG & LChV \\
\hline Arecaceae & Sabal yapa C.Wright ex Becc. & Guano & Palma & & LG & LChV \\
\hline \multirow[t]{2}{*}{ Cactaceae } & Selenicereus donkelaarii (Salm-Dyck) & & & & & \\
\hline & Britton \& Rose & Pitaya de monte & Trepadora & & LG & LChV \\
\hline Erythroxylaceae & Erythroxylum areolatum $\mathrm{L}$. & - & Árbol & & LG & LChV \\
\hline Fabaceae & Lonchocarpus longistylus Pittier & Balché & Árbol & & LG & LChV \\
\hline \multirow{3}{*}{$\begin{array}{l}\text { Fabaceae } \\
\text { Loranthaceae }\end{array}$} & Acacia cornigera (L.) Willd. & Subín & Árbol & & LG & LChV \\
\hline & Phoradendron quadrangulare (Kunth) & & & & & \\
\hline & Krug \& Urban & Matapalo & Parásita & & LG & LChV \\
\hline Malvaceae & Malvaviscus arboreus Cav. & -- & Arbusto & & LG & LChV \\
\hline Passifloraceae & Passiflora foetida L. & Jujo de monte & Enredadera & & LG & LChV \\
\hline Poaceae & Lasiacis ruscifolia (Kunth) Hitchc. & - & Hierba & & LG & LChV \\
\hline Poaceae & Paspalum sp. & -- & Hierba & & LG & LChV \\
\hline Polygonaceae & Coccoloba floribunda (Benth.) Lindau & -- & Árbol & & LG & LChV \\
\hline Polygonaceae & Coccoloba humboldtii Meisn. & Boop' & Árbol & & LG & LChV \\
\hline Polygonaceae & Coccoloba uvifera (L.) L. & -- & Árbol & & LG & LChV \\
\hline Polygonaceae & Gymnopodium floribundum Rolfe & tzitzilché & Árbol & & LG & LChV \\
\hline Polypodiaceae & Acrostichum aureum L. & Helecho & Hierba & & LG & LChV \\
\hline Polypodiaceae & Microgramma nitida (J. Sm.) A. R. Sm. & Helecho & Hierba & & LG & LChV \\
\hline Portulacaceae & Portulaca $s p$. & - & Hierba & & LG & LChV \\
\hline Smilacaceae & Smilax mollis Humb. \& Bonpl. ex Willd. & -- & Enredadera & & LG & LChV \\
\hline Teophrastaceae & Jacquinia aurantiaca W.T. Aiton & & Arbusto & & LG & LChV \\
\hline Apocynaceae & Thevetia gaumeri Hemsl. & Akitz & Arbusto & EC & & \\
\hline Polygonaceae & Coccoloba reflexiflora Standl. & -- & Árbol & EC & & \\
\hline
\end{tabular}


Tabla 1. Ubicación de las especies en los cuerpos de agua (continuación).

\begin{tabular}{|c|c|c|c|c|}
\hline Familia & Especie & $\begin{array}{l}\text { Nombre } \\
\text { común }\end{array}$ & $\begin{array}{l}\text { Forma de } \\
\text { vida }\end{array}$ & $\begin{array}{l}\text { Cuerpos de agua donde } \\
\text { está presente la especie }\end{array}$ \\
\hline Asteraceae & Viguiera dentata (Cav.) Spreng. & Julub & Hierba & EC \\
\hline Boraginaceae & Cordia dodecandra DC. & Ciricote & Árbol & EC \\
\hline \multirow{2}{*}{ Cactaceae } & Tillandsia fasciculata Sw. & neh ku'uk & Epífita & $\mathrm{EC}$ \\
\hline & $\begin{array}{l}\text { Selenicereus testudo (Karw. } \\
\text { ex Zucc.) Buxb. }\end{array}$ & Pitaya de monte & e Trepadora & EC \\
\hline Cyperaceae & Rhynchospora colorata (L.) H. Pfeiff. & - & Herbácea & EC \\
\hline Chrysobalanaceae & Chrysobalanus icaco L. & Icaco & Árbol & EC \\
\hline Euphorbiaceae & Croton reflexifolius Kunth & Cascarillo & Árbol & EC \\
\hline & Haematoxylum campechianum L. & Palo de tinte & Árbol & EC \\
\hline Fabaceae & $\begin{array}{l}\text { PIthecelloblum recordII } \\
\text { (Britton \& Rose) Standl. }\end{array}$ & -- & Árbol & $\mathrm{EC}$ \\
\hline Lauraceae & Nectandra salicifolia (Kunth) Nees & -- & Árbol & EC \\
\hline Gentianaceae & Lisianthius axillaris (Hemsl.) Kuntze & Chilillo & Arbusto & EC \\
\hline \multirow[t]{2}{*}{ Gentianaceae } & Eustoma exaltatum (L.) Salisb. & & & \\
\hline & ex G. Don. & -- & Herbácea & EC \\
\hline Moraceae & Brosimum alicastrum Sw. & Ramón & Arbol & EC \\
\hline Myrtaceae & Psidium sartorianum (O. Berg) Nied. & Guayabillo & Árbol & $\mathrm{EC}$ \\
\hline Nymphaeaceae & Nymphaea ampla (Salisb.) DC. & $\begin{array}{l}\text { Flor de agua, } \\
\text { ninfa }\end{array}$ & Acuática & EC \\
\hline Orchidaceae & Bletia purpurea (Lam.) DC. & Orquídea & Subacuática & EC \\
\hline Orchidaceae & Brassavola nodosa (L.) Lindl. & Orquídea & Epífita & $\mathrm{EC}$ \\
\hline Orchidaceae & Epidendrum nocturnum Jacq. & Orquídea & Epífita & EC \\
\hline Orchidaceae & Polystachya clavata Lindl. & Orquídea & Epífita & EC \\
\hline Orchidaceae & Rhyncholaelia digbyana (Lindl.) Schltr. & Orquídea & Epífita & $\mathrm{EC}$ \\
\hline Poaceae & Panicum maximum Jacq. & -- & Hierba & EC \\
\hline Polypodiaceae & Polypodium lycopodioides L. & Helecho & Hierba & EC \\
\hline Rubiaceae & Borreria verticillata (L.) G. Mey. & & Herbácea & EC \\
\hline Rubiaceae & Morinda yucatanensis Greenm. & Tunche & Trepadora & EC \\
\hline Sapindaceae & Talisia oliviformis (Kunth.) Radlk. & Huaya & Árbol & EC \\
\hline Solanaceae & Solanum verbascifolium C.B. Wright & Tukuy & Arbusto & EC \\
\hline Verbenaceae & Vitex gaumeri Greenm. & Yaaxnik & Árbol & EC \\
\hline
\end{tabular}

EC: El Creek LG: Laguna Guerrero LChV: Laguna Chile Verde

dante en la orilla, mientras que el pasto aguja está sobre todo en la orilla.

a) Asociación de ninfa o flor de agua ( $N$. ampla). La especie dominante de esta vegetación es $N$. ampla, que es una especie emergente y que se distribuye a lo largo de casi todo El Creek (Figura 2), tanto en el centro del cuerpo de agua como junto a los bordes y en los recodos donde la corriente se mantiene en calma. Esta planta permanece en crecimiento en el fondo del cuerpo de agua y luego empieza a desarrollar un pecíolo que llega a alcanzar hasta $3 \mathrm{~m}$ de largo (dependiendo de la profundidad del agua), el cual finalmente quedará coronado por una sola hoja, la misma que flota sobre la superficie del agua y que tiene entre 20 y $40 \mathrm{~cm}$ de diámetro; al tiempo de la floración se desarrolla un soporte, que sostiene a una sola flor; este soporte tiene la misma longitud que el pecíolo de la hoja. N. ampla presenta floración durante todo el año, por lo que le da un to- que hermoso al paisaje que se puede admirar en los recorridos turísticos que se llevan a cabo en El Creek.

b) Asociación de pasto aguja (E. cellulosa). Esta especie se distribuye ampliamente en el borde El Creek, pero sobre todo se presenta en parches con individuos numerosos y dispersos, aunque en algunas orillas se distribuye en asociaciones muy densas, y termina por invadir un poco el área que está sobre el talud de la ribera. E. cellulosa tiene una altura total entre $60 \mathrm{~cm}$ y $1 \mathrm{~m}$. Este tipo de vegetación se manifiesta en zonas en donde se mantienen condiciones de aguas someras y con poco movimiento.

2. Vegetación de manglar. El manglar es una asociación vegetal que aparece en la orilla de lagunas, riberas de ríos con poca corriente, o en estuarios y deltas; casi siempre es una asociación costera (RicoGray 1982). Los manglares son vegetales halófilos facultativos, es decir que pueden tolerar rangos variables de salinidad y tienen estructuras especializa- 
das en el control de las sales internas (Foroughbakhch et al. 2004), por lo que esta es absorbida a través de las raíces de la planta y es eliminada por las hojas, llegando a formar una capa de sal en su superficie (Fueyo 2008). El manglar está asociado con los cuerpos de agua, lagunas, ojos de agua, o manantiales y se desarrolla bien, debido a las elevadas concentraciones de nutrientes, baja salinidad y suelos con una gruesa capa de materia orgánica (Herrera y Ceballos 1998 , et al. 2011). R. mangle y L. racemosa son las especies dominantes en estas lagunas y su estructura presenta algunas variantes, dependiendo del lugar donde se encuentre, desarrollando una mayor riqueza florística intrínseca en las riberas (Flores et al. 2011). En la Laguna de Bacalar, el manglar se distribuye en áreas que están por debajo del nivel medio del mar, y por lo mismo son zonas sujetas a períodos de inundación intermitente. El manglar (Figura 2) se puede diversificar integrando distintas asociaciones vegetales y en El Creek, existen al menos dos asociaciones, con sus respectivas características fisionómicas, la de vegetación de galería con predominancia de mangle rojo y la de vegetación de galería con predominancia de mangle botoncillo.

a) Vegetación de galería con predominancia de mangle rojo ( $R$. mangle). Esta asociación vegetal está sujeta a procesos hidrológicos estuarinos, bajo la influencia de agua salobre y agua dulce que surge de la parte interna de las cuencas inundables. Específicamente en El Creek, la asociación de mangle rojo, tiene entre 4 y $7 \mathrm{~m}$ de altura y está conformada mayoritariamente por $R$. mangle (mangle rojo), pero también se pueden hallar algunos elementos de $C$. erectus (mangle botoncillo), de L. racemosa (mangle blanco), de B. buceras (pukté) y de P. sartorianum («guayabillo»), además de una gran cantidad de hierbas, bejucos y epífitas asociadas con estos árboles, entre las que podemos ver hierbas erectas como V. dentata, B. verticillata, y M. yucatanense y orquídeas que se desarrollan sobre las ramas del manglar, como $R$. digbyana, $B$. nodosa, $P$. clavata y E. nocturnum, bromeliáceas epífitas como $T$. bulbosa, T. dasyliirifolia, T. streptophylla y $T$. fasciculata, y cactáceas epífitas como $S$. testudo.

b) Vegetación de galería con predominancia de mangle botoncillo (C. erectus) y mangle blanco (L. racemosa). Algunos autores dicen que $C$. erectus (conocido como mangle botoncillo) no es un manglar en el sentido estricto, porque no germina en la propia planta (germinación vivípara), pero en general se considera y se conoce así, como mangle botoncillo (Rodríguez y Vázquez-Lule 2006, López et al. 2010). La vegetación de galería que está representada mayoritariamente por mangle botoncillo (C. erectus) y mangle blanco (L. racemosa), a lo largo de la Laguna de Bacalar, tiene un área de distribución restringida, que son los terrenos bajos que bordean esta Laguna. Este tipo de manglar aparece en zonas ubicadas hacia el interior de la zona continental y es más amplio y de mejor desarrollo sobre sustratos y zonas de inundación con menor porcentaje de sales y la baja tolerancia a la salinidad que presentan estas especies, se acentúa cuando se recibe un gran aporte de agua dulce proveniente de la precipitación pluvial. Específicamente en la zona de El Creek, estos mangles son los elementos fuertemente dominantes y llegan a alcanzar una altura de entre 3 y $8 \mathrm{~m}$ (y de 8 a $12 \mathrm{~cm}$ de DAP) y el sustrato donde se distribuye es limo-arcilloso y relativamente somero.

En El Creek, el mangle botoncillo-mangle blanco es una asociación relativamente diversa, porque se pueden incorporar otros árboles como $M$. zapota (chicozapote), M. brownei (chechem negro), Icaco (C. icaco), B. buceras (pukté) y $N$. sanguinea (laurelillo), así como varias hierbas como $R$. holoschoenoides, $C$. jamaicense, $R$. colorata, $B$. verticillata; trepadoras como $R$. biflora; arbustos como B. tubiflora (sulub) y $S$. verbascifolium (tukuy), y además parásitas como $P$. calyculatus (matapalo). Aunque los árboles, que aparecen en esta asociación vegetal son propios de selvas bajas y medianas, se desarrollan intercalados con el mangle botoncillo-mangle blanco, o pueden aparecer al otro lado del manglar, ya prácticamente sobre la zona continental.

En Laguna Guerrero, hay mangle botoncillo ( $C$. erectus), mangle blanco (L. racemosa), junto con el pukté (B. buceras) y las palmas de coco ( $C$. nucifera) y algunas hierbas, como portulacáceas (Portulaca) y gramíneas Paspalum sp. En aguas interiores, la vegetación de la ribera, la de galería y la de la parte continental, no cambia mucho, es relativamente homogénea hay mangle botoncillo $(C$. erectus), mangle blanco (L. racemosa), mangle rojo (R. mangle), pukté (B. buceras), tasiste (A. 
wrigthtii) y chechén (M. brownei). Sin embargo, conforme se avanza, esa composición florística cambia (Figura 3). Abundan las cortaderas ( $C$. jamaicense), en la orilla de la laguna, junto mangle rojo ( $R$. mangle), con bromeliáceas epífitas ( $T$. dasyliirifolia), además de mangle botoncillo $(C$. erectus), y al fondo, es decir, hacia la zona continental, hay selva baja y un poco más hacia el norte de la Laguna, se observa la presencia de mangle rojo $(R$. mangle), cortadera ( $C$. jamaicense), mangle botoncillo ( $C$. erectus), corcho (A. glabra), mangle blanco (L. racemosa), zapote (M. zapota), chechén (M. brownei), crucetilla ( $R$. aculeata), orquídea epífita (O. ascendens) y $R$. biflora.

En la Laguna Chile Verde, se observa que a pesar de las actividades humanas de esparcimiento, natación, puestos de comida, etc., la vegetación riparia y de galería aparentemente no está demasiado deteriorada. Hay mangle botoncillo (C. erectus), mangle blanco ( $L$. racemosa) y pukté (B. buceras), y una gran cantidad de cormoranes o camachos $(P$. olivaceus) que pueblan la laguna. Más hacia el interior, además del C. erectus y L. racemosa, hay mangle rojo ( $R$. mangle), cyperáceas acuáticas $(E$. cellulosa), pasto cortadera (C. jamaicense), cactáceas cilíndricas ( $S$. donkelaari) y D. glabra. Más hacia el norte de la Laguna, se puede observar una gran asociación de E. cellulosa en la orilla de la laguna y después una franja de mangles (en su mayoría mangle rojo $R$. mangle), que se termina donde está la zona fangosa; esta franja de manglares (de menos de $50 \mathrm{~m}$ de ancho) también incluye pasto cortadera (Figura 4), en bajas cantidades. Después de ello, aparecen los elementos de selva mediana que se encuentran aquí, palmas de tasiste (A. wrightii), zapote (M. zapota), chechen (M. brownei), chaká (B. simaruba), y jabín (P. piscipula), además de algunos arbustos y al avanzar sobre ese trayecto, encontramos cada vez menos individuos de E. cellulosa y más de D. glabra, J. aurantiaca y una Loranthaceae de flores blancas ( $P$. piperoides).

c) Petenes. Los petenes son islas de vegetación arbórea localizadas dentro de las marismas, y son asociaciones vegetales restringidas a la Península de Yucatán. Las especies características son el mangle rojo, mangle botoncillo y arecáceas (Valdéz e Islebe 2012) y estas especies las podemos encontrar en las dos lagunas; por ejemplo, en la Laguna Guerrero, donde se registró una zona continental abrupta, con cactáceas cilíndricas ( $S$. donkelaari), bromelia ( $T$. streptophylla), tasiste (A. wrightii), orquídea $(O$. ascendens), campana (Ipomoea sp.), jabin ( $P$. piscipula), bambusoideae pequeña (L. ruscifolia), mahagua (H. trilobata), tzalam (L. bahamensis), $P$. foetida, ciricote ( $C$. dodecandra), bromeliáceas epífitas (chu') T. dasyliriifolia; toh'yub ( $G$. floribundum), chechén (M. brownei) con frutos, $A$. cornigera, M. arboreus. Mientras que en la Laguna Chile Verde, en islas similares, pudimos ver algunas palmas de tasiste (A. wrightii) y pasto cola de venado (A. glomeratus) y una buena diversidad de hierbas, arbustos y árboles, como chechén $(M$. brownei), chicozapote (M. zapota), D. glabra, $C$. humboldtii, pasto cortadera (C. jamaicense), tasiste (A. wrightii), hulubal (B. tubiflora), bromelia ( $T$. dasyliriifolia), pukté (B. buceras), cactácea cilíndrica (S. donkelaari) y E. areolatum.

3. Vegetación subacuática. Las comunidades vegetales ligadas con el medio acuático o el suelo que llega a estar saturado con agua de manera intermitente son muy variadas (Lembi 2009). Es una vegetación dispersa y con limitada tolerancia a los factores ambientales (temperatura, luminosidad, $\mathrm{pH}$, salinidad, concentración de oxígeno, etc.). Son más complejas en estructura y organización y tienen tejidos especializados, como raíces, hojas, tallos y flores (Parker 2005). Las especies que conforman este tipo de vegetación se concentran sobre todo en las zonas cercanas al nivel de la Laguna y en áreas donde la precipitación relativamente alta coincide con muchas áreas de difícil drenaje. En El Creek encontramos básicamente tres tipos: la asociación de cortadera $(C$. jamaicense), la asociación de zacate ch'it suuk ( $A$. glomeratus) y el saibal-manglar.

a) Asociación predominante de cortadera $C$. jamaicense, y otras hierbas, como $R$. colorata, $V$. dentata, chilillo (L. axilaris). La asociación de cortadera en El Creek se ubica a manera de parches en áreas de terreno bajo. C. jamaicense (también conocida como navajuela o como saiba), se desarrolla muy bien en el período de inundación intermitente. La cortadera es una planta herbácea que en promedio tiene $80 \mathrm{~cm}$, pero en algunos sitios, sobre todo en sustratos muy someros, llega a tener más de $2 \mathrm{~m}$ de altura y densidades mayores a 10 individuos por $\mathrm{m}^{2}$. La principal fuente hídrica de esta comunidad, pro- 
viene del incremento del nivel de inundación del cuerpo de agua durante la temporada lluviosa del año. Los suelos donde se desarrolla esta asociación son gleysoles mólicos y eútricos, profundos, poco permeables, ligeramente salinos, con gran acumulación de limo y carbonato de calcio.

b) Asociación de zacate ch'it suuk o cola de venado (A. glomeratus) y otras hierbas. El área de vegetación inundable El Creek hacia la parte continental, inicia con una mezcla entre individuos de $C$. jamaicense y A. glomeratus y casi inmediatamente después, está la franja prácticamente homogénea de esta gramínea (cuya espiga semeja una cola de venado) y que se conoce como zacate ch'it suuk.

Esta asociación casi pura de A. glomeratus se desarrolla sobre una zona inundable, pero que ya se constituye como suelo firme y un poco más arcilloso y con drenaje deficiente. Este zacate tiene en promedio $1 \mathrm{~m}$ de altura y más de 5 individuos por $\mathrm{m}^{2}$. Las condiciones que permiten el establecimiento de esta franja de zacate, son las inundaciones intermitentes de la zona riparia, las condiciones de escaso drenaje y saturación del sustrato, y la dispersión de esta planta a través de estolones. Algunas hierbas que se pueden encontrar en la asociación de $A$. glomeratus, son el juluval ( $V$. dentata), cortadera $(C$. jamaicense), chilillo ( $L$. axillaris) y $B$. verticillata. Inmediatamente después de esa franja de zacate $c h$ 'it suuk (siempre hacia la zona continental), se puede ver una combinación de vegetación inundable y sabana, constituida por $A$. glomeratus, $C$. jamaicense y árboles como chechen (M. brownei), tinto $(H$. campechianum), chicozapote ( $M$. sapota), saklop (C. diversifolia), akits (T. gaumeri), tzalam ( $L$. latisiliqua), C. yucatanensis, chaká (B. simaruba) y pukté (B. buceras), entre otras especies. Esta última asociación corresponde a la «selva baja inundable con pukté» que se detalla más adelante.

c) Saibal-Manglar con cortadera (C. jamaicense), mangle botoncillo (C. erectus) y palma tasiste (A. wrightii) y otras hierbas asociadas como B. purpurea, P. maximun, C. filiformis y algunos individuos de C. reflexiflora. Se le llama saibal-manglar (C. jamaicense, se conoce como saiba, precisamente porque no es posible realizar una clara separación entre los elementos florísticos que integran esta asociación, ya que ambas son asociaciones que se hacen manifiestas en zonas sujetas a algún grado de inundación, situación que se ve favorecida por toda la zona en donde hay una topografía marcadamente plana y casi al nivel del cuerpo de agua.

El saibal-manglar es una asociación integrada por numerosas especies de monocotiledóneas (Cladium y Andropogon, entre otras), especies de hojas angostas y sin órganos foliares flotantes (Rzedowski 2006). En esta situación, se puede presentar alguna corriente hacia los cuerpos de agua cercanos; los principales aportes de agua que sostienen a este tipo de vegetación provienen de la precipitación pluvial.

Estas asociaciones cubren una gran extensión del territorio, justo en la zona de transición entre el manglar y la orilla de la zona continental (Valdéz e Islebe 2012) y se integran con elementos mezclados con las asociaciones de Cladium y Andropogon. Algunas de las especies que conforman este tipo de vegetación, aparecen también en otras zonas que ya prácticamente pertenecen a la zona continental.

El saibal-manglar presenta como especies dominantes a la planta herbácea Cladium jamaicense (navajuela o cortadera o saiba), que se mezcla con elementos arborescentes como son mangle botoncillo (C. erectus), pukté (B. buceras), y tasiste (A. wrightii). De esta forma, se integra una asociación muy densa, presentando de 1 a $5 \mathrm{~m}$ de altura. En áreas abiertas, se presentan de manera dispersa especies de herbáceas como son: E. exaltatum, $E$. geniculata, F. cymosa y M. procumbens. El suelo que soporta a esta asociación es profundo, de tipo gleysol mólico y eútrico, poco permeables, ligeramente salino, con gran acumulación de limo y carbonato de calcio.

En la Laguna Guerrero, hay zonas donde se puede observar grandes asociaciones de cortadera $(C$. jamaicense) y mangle botoncillo y rojo, de baja altura (Figura 3), algunos tasistes (A. wrightii). Las «carpetas» de cortadera ( $C$. jamaicense) cubren mucho del paisaje y avanza a lo largo de la ribera por unos $20 \mathrm{~m}$, para después aparecer una asociación de mangle ( $R$. mangle).

En la Laguna Chile Verde, también se puede encontrar $C$. jamaicense, junto con mangle botoncillo (C. erectus) y ciperáceas acuáticas (E. cellulosa y F. cymosa), pasto cortadera (C. jamaicense), así como algunos arbustos, como D. glabra y pastos (Figura 4) como A. glomeratus, antes de llegar a la 
zona continental donde hay árboles más altos que en los otros puntos.

4. Vegetación arbórea en bajos inundables. En algunas partes de la ribera de la Laguna de Bacalar, el terreno ha quedado ligeramente más bajo, lo que ha llevado a cambios notorios en la fisonomía de la vegetación; en las zonas relativamente más altas se manifiesta una vegetación de selva baja subcaducifolia o de selva mediana (o incluso selva alta) subperennifolia; mientras que en las zonas bajas se distribuye una vegetación adaptada a proceso de inundación temporal. Se supone que en estas zonas el cambio relativo de la topografía provoca que durante la temporada lluviosa del año permanezcan parcial o totalmente inundadas y toda la lluvia fluye de los terrenos más elevados a los más bajos. No obstante, dada la existencia de mantos rocosos superficiales, esta tiende a estancarse y esta situación es muy adecuada para una serie de comunidades vegetales que se han adaptado a esta condición, una de ellas y que está presente en la zona continental de la ribera El Creek, es la selva baja inundable con $B$. buceras (pukté) y $C$. reflexifolius (cascarillo).

Las selvas caducifolias se desarrollan en climas del trópico húmedo y subhúmedo en condiciones de anegación total del suelo en la temporada de lluvias, que se seca durante el estiaje (Challenger y Soberón 2008) y constituyen el límite térmico e hídrico de los tipos de vegetación de las zonas cálido-húmedas (Pennington y Sarukhán 1998). Las selvas bajas caducifolias tienen un componente endémico muy importante, $25 \%$ al nivel de género y $40 \%$ al de especie. Estas selvas incluyen la selva baja subcaducifolia (Rzedowski 1978). La dominancia de esta comunidad está dada a menudo por una o dos especies (Rzedowski 1998), en las que las trepadoras son muy escasas, y en cambio las epífitas de tipo xerófilo de porte pequeño, como las del género Tillandsia, pueden en ocasiones cubrir densamente las ramas de los árboles. Los diámetros de los árboles en la selva baja subcaducifolia, oscilan entre 1 y $59,4 \mathrm{~cm}$ y se tienen las siguientes especies: B. simaruba, Caesalpinia gaumeri, Coccoloba cozumelensis, Guettarda elliptica, Hippocratea excelsa, Karwinskia humboldtiana, Lysiloma latisiliquum, M. zapota, Maytenus schippii, M. brownei, Neea psychotrioides, P. piscipula, P. sartorianum, T. oliviformis, Thouinia paucidentata y V. gaumeri; los DAP máximos son de 30 a $60 \mathrm{~cm}$. Los valores de diversidad de especies (índice de Shannon-Wiener) para 0,2 ha y 0,1 ha, son de 5,8 y 4,2 respectivamente y el patrón de abundancia relativa muestra un comportamiento característico de las selvas tropicales en donde unas pocas especies son las más abundantes (Gutiérrez et al. 2011). Muchos elementos de la selva baja subcaducifolia, están entre la zona riparia y la zona continental.

b) Selva baja inundable con pukté (B. buceras) $\boldsymbol{y} \boldsymbol{C}$. reflexifolius. Esta vegetación comprende amplias áreas de distribución en la zona continental de El Creek. Esta asociación vegetal se distribuye preferentemente hacia las zonas de terreno más o menos plano que se encuentra bordeada por muy ligeras elevaciones. La lluvia es el principal factor de inundación y son plantas que van hacia la zona continental, en un ecotono herbáceo (Díaz y Rosales 2006). La zona continental, conformada en su parte riparia por cortadera y algunos individuos de tzalam $(L$. latisiliquum), tinto (H. campechianum), chicozapote (M. zapota), ramón (B. alicastrum), chaká ( $B$. simaruba), y guayabillo ( $P$. sartorianum). Sin embargo, esta asociación, se caracteriza precisamente por la dominancia en el estrato arbóreo del pukté ( $B$. buceras), una especie que en las orillas de El Creek tiene en promedio alturas de $4 \mathrm{~m}$ y DAP promedio de $15 \mathrm{~cm}$. La composición florística se complementa con numerosos individuos de C. reflexifolius (cascarillo), $H$. trilobata (majagua), C. reflexiflora, M. brownei (chechem) y T. gaumeri (akitz), entre otras. En su conjunto estas especies alcanzan entre 3 y $7 \mathrm{~m}$ de altura y DAP promedio de $8 \mathrm{~cm}$. Además, hay algunas especies arbustivas y un estrato herbáceo que está integrado de ciperáceas anuales como $R$. colorata. El suelo de esta área es poco permeable y con abundante materia orgánica acumulada.

En la Laguna Chile Verde, también podemos encontrar «bajos» con fango arenoso y profundo (de casi medio metro de profundidad) y con varios arbustos (Figura 4), como D. glabra y ciperáceas acuáticas entre ellas $F$. cymosa.

5. Vegetación arbórea baja. Aunque en estas regiones, la zona con características propias para la distribución de la vegetación de selva o bosque tropical, corresponde a los sitios más alejados del mar, algunos elementos de esta vegetación se encuentran presentes en las partes más altas y sobre la zona 
continental del área que rodea a la Laguna de Bacalar. Es una zona de terreno firme, donde la topografía se eleva por arriba de los 8 y 10 metros de elevación y esa escasa diferencia de altura es suficiente para servir de límite a los terrenos bajos y cenagosos en los cuales se distribuye el manglar y algunas comunidades acuáticas con influencia lagunar o marina, por lo que el lugar es cubierto por una vegetación exuberante de selva.

a) Selva baja subcaducifolia; con palma de chit (T. radiata), yaaxnik (V. gaumeri), y chicozapote (M. zapota). La vegetación de selva baja subcaducifolia se distribuye sobre un terreno de amplitud variable, en una franja que bordea a la Laguna de Bacalar. Aunque la delimitación de esta vegetación no es muy precisa es posible que muchas asociaciones que parecen corresponder a este tipo de vegetación, en realidad correspondan a estados sucesionales de esta vegetación. Es una selva de transición, integrando un enlace natural entre la selva mediana subperennifolia (con árboles de gran corpulencia, de más de $10 \mathrm{~m}$ de altura y DAP superiores a $\operatorname{los} 20 \mathrm{~cm}$ ) y las zonas bajas sujetas a inundación que se cubren con vegetación de manglar y otras comunidades.

Específicamente en El Creek, este tipo de vegetación está en las partes más alejadas al cuerpo de agua, pero constituye uno de los estratos de vegetación del paisaje (Figura 2). Como parte de los elementos caducifolios que componen esta vegetación se puede encontrar a B. simaruba (chaká), $L$. latisiliquum (tzalam), y P. piscipula (habin), entre otros. En el caso de los perennifolios se tiene a $M$. zapota (chicozapote) y T. olivaeformis (huaya), entre muchos otras. Esta vegetación de selva baja también presenta un estrato arbustivo de entre 1 y $4 \mathrm{~m}$ de altura y también están presentes otros elementos como $N$. coriacea (laurel), M. arboreus (tulipán de monte) y $R$. aculeata (cruceta). Los factores físicos que condicionan la distribución de esta asociación corresponden a la presencia de suelos ligeramente más elevados, de entre 10 a $30 \mathrm{~cm}$ de profundidad y que favorecen un drenaje más eficiente, así como una mayor cantidad de materia orgánica en descomposición.

6. Vegetación secundaria. Es aquella que crece después de una perturbación; por ejemplo, la vegetación originada después de roza-tumba-quema, entre la población Maya es conocida como acahual. Las especies más comunes son el guarumbo (Cecropia obtusifolia), ka's kaat (Luehea speciosa) y jabín (Piscidia piscipula). En el sur de Quintana Roo se desarrollan selvas más verdes y altas porque en esta zona se registra una mayor precipitación (Valdéz e Islebe 2012). Es hacia la zona continental de ambas lagunas (Guerrero y Chile Verde), donde predominan algunos manchones de este tipo de vegetación. El ambiente con alto grado de humedad propio de estos lugares favorece la distribución de numerosas especies de plantas epifitas (sobre todo orquídeas y bromeliáceas). Por otra parte, la vegetación secundaria, alcanza valores de diversidad florística de 1,01 y aún más bajos para aquellas áreas de intenso aprovechamiento. En esta área se distribuyen varios tipos de vegetación, como la vegetación semiacuática riparia y de galería, además del manglar (con mangle rojo, mangle botoncillo y mangle blanco, en ese orden de importancia); es necesario considerar la vegetación acuática con predominancia de E. cellulosa y más hacia la zona continental, $C$. jamaicense y el manglar-saibal (con A. glomeratus), etc., toda esta vegetación alberga una serie importante de fauna.

\section{Discusión}

Uno de los atractivos más importantes de las zonas turísticas de aventuras, lo constituye la biodiversidad que lo circunda y esta característica puede cambiar en función del ambiente. Acorde con Ward (1988), los paisajes inundables, se integran con una serie de biotopos y gradientes ambientales, con sus comunidades bióticas; de tal manera que el desequilibrio en algunos de estos componentes, repercute en otros; así que ante la inminencia de la influencia antropogénica, se deben plantear soluciones congruentes con el desarrollo social y económico de la gente que vive en el entorno natural. En el caso de los centros turísticos naturales asociados con cuerpos de agua, en la península de Yucatán en México, se pueden encontrar básicamente tres formas: cenotes, zonas con corrientes lénticas y zonas con corrientes lóticas. Los cenotes son depresiones grandes del suelo rocoso, que se generan desde arriba, por infiltración pluvial y desde abajo, por circulación subterránea, hasta que «el techo» colapsa (Beddows et al. 2003); 
en los cenotes se almacena mucha agua y hay vegetación ligada a los ambientes rupícolas húmedos como helechos, ramón (B. alicastrum), guarumo (Cecropia peltata L.), lianas y epífitas; y en las corrientes lénticas, el atractivo más importante son las plantas acuáticas estrictas sobre todo N. ampla, los mangles, el pucté (B. buceras) y las epífitas asociadas con ellos, de tal manera que los turistas incluso pueden descender (del recorrido en lancha) y entrar en contacto con las plantas, así como admirar la fauna ligada a este tipo de vegetación; y en las corrientes lóticas; lo destacable para el turismo, son los mangles, palmares y orquídeas; y para lóticas y lénticas, la belleza de los islotes de vegetación, conocidos como petenes, que de acuerdo a Durán (1995) se definen como pequeñas islas de vegetación arbórea, principalmente de selva mediana subperennifolia y de manglar, que se encuentran inmersas en medio de amplias zonas inundables de tipo pantanoso (marismas), se distribuyen en todo el borde de la Península de Yucatán y poseen tanto elementos de la vegetación de galería como de la riparia.

En las lagunas (Guerrero y Chile Verde) predominan la vegetación subacuática, de galería, riparia, y la de zonas inundables debido a que mayormente, la distribución de especies acuáticas está adecuada con la presencia de aguas salobres, y en los cuerpos interiores de agua dulce (en zonas lénticas), el agua se modifica para permitir la distribución de fanerógamas acuáticas emergentes; aunque en el estudio realizado, se encontraron pocas plantas acuáticas estrictas, presumiblemente porque en las corrientes lóticas la vegetación acuática estricta aparece en forma solamente marginal o casi nula, características que reflejan la fragilidad de estos ecosistemas.

A pesar de que las especies y ambientes de agua dulce están considerados como los más frágiles y amenazados por las perturbaciones derivadas del uso del suelo, por la alteración de las hidrologías, por la introducción de especies no nativas (Saunders et al. 2002), por la basura y por los desechos agrícolas (Allan y Flecker 1993), existen formas de encontrar una coexistencia, y aún un desarrollo sustentable entre la protección de los ecosistemas, el desarrollo económico y el mejoramiento de la sociedad y una de esas formas puede ser el turismo de aventura, como es el caso presente en la zona de estudio, en donde no solamente se puede pensar en la economía sino también en la conservación.
Sin embargo, para plantear programas serios de conservación, primero es necesario, conocer los componentes del ecosistema, y con base en ello, saber el punto de equilibrio del ecoturismo racional y controlado (Saunders et al. 2002); una vez identificado el ambiente natural en cuestión, se debe conocer con detalle el ecosistema, y en función de ello, después, plantear los objetivos y las modalidades de conservación (Groves et al. 2002). Sólo en el caso de que se plantee el turismo de aventura como alternativa, se deben de analizar los potenciales de las corrientes de agua, las especies presentes y los nichos de esas especies (Cálix de Dios et al. 1996). Visto así, es factible el turismo de aventura como forma de desarrollo local y como estrategia de conservación ecológica; varios pueblos han venido cambiando la naturaleza del turismo, ya sea a agro-turismo, turismo de aventura, pesca y repesca, viajes con cazadores en la selva, etc, actividades que en su conformación rural, pueden ayudar a mejorar su economía (Maruti 2009); sin embargo, es necesario el conocimiento de los recursos naturales y su ecología, antes de iniciar un proyecto ecoturístico (Zur Heide 2012), como en el caso de los sistemas acuáticos de la Península de Yucatán, en México.

Uno de los sistemas acuáticos más conocidos en el sur del estado de Quintana Roo, es la Laguna de Bacalar. Además de la importancia ecológica que representa para esta región, varios poblados, centros turísticos y recreativos comparten este cuerpo de agua, y muchas familias perciben ingresos relacionados con este sistema lacustre. A pesar de que en El Creek (la comunidad se llama «Pedro A. Santos») las actividades recreativas son de bajo impacto, se hace necesario el conocimiento de las características de la vegetación que rodea a su cuerpo de agua, considerando también la producción agrícola del ejido, que destaca en la producción de piña, y algo de ganadería, junto con una gran cubierta forestal, museo, y venta de artesanías de la región (CDI 2009); caso un poco diferente al de las comunidades de «Laguna Guerrero»y «Chile Verde» (el poblado se llama «Raudales»), que tienen su origen en asentamientos iniciales de chicleros y madereros de mediados del siglo pasado; y hoy «Raudales» es una zona básicamente agrícola (con cultivos de coco, papaya, naranja dulce, limón, toronja, chile serrano, pepino, aguacate, guayaba, nance, guanábana, guaya, 
zapote, mango, tamarindo, anona, etc.), y turismo de bajo impacto, que les aportan ingresos, por el uso de los cuerpos de agua (las lagunas); de tal manera que dado el paulatino avance del incremento de este último giro, surge la necesidad de conocer los componentes naturales de estos cuerpos acuáticos; asumiendo, con la información obtenida que las comunidades de estos poblados (incluyendo a El Creek), poseen características potenciales para una gran gama de actividades productivas, como pesca y deportes acuáticos, entre otras. Además, de que la zona continental de sus cuencas puede tener utilidad productiva agrícola, ganadera, y como área de turismo alternativo. Sin embargo, se requiere de la aplicación de criterios precisos de conservación, como por ejemplo, ponderar y analizar las diferencias ecológicas entre las zonas bajas o inundables, que son terrenos que se ubican por debajo del nivel de piso de las selvas medianas (y altas) subperennifolias, y que se llegan ha convertir en vasos captadores del agua de lluvia y constituyen una importante fuente de abastecimiento de agua para la fauna silvestre durante la época más seca del año; las lagunas, propiamente dichas, que permanecen con agua todo el año y que se pueden usar como áreas recreativas y de turismo de aventura pero siempre realizando estudios que permitan una adecuada ordenación territorial y medioambiental de las actividades turísticas, acorde con lo sugerido por Sánchez y Batres (2007), porque es indispensable evitar que las actividades turísticas alteren, reduzcan o supriman los hábitats acuáticos naturales y paralelamente afecten la vegetación circundante de estos sitios, provocando su deterioro o su extinción, tal como lo mencionan Ramos y Novelo (1993).

Por la profunda alteración que sufren los recursos acuáticos por urbanismo o por la industria (MoraOlivo et al. 2013) y debido al conocimiento fragmentario que se tiene de la vegetación acuática y subacuática de los lagos continentales en México, es importante realizar estos trabajos para conocer toda esta biodiversidad. Esta diversidad biológica está asociada con los escurrimientos superficiales que conducen las aguas de la Laguna de Bacalar al río Hondo y luego a la Bahía de Chetumal. En el caso de esta vegetación, probablemente se mantiene un alto grado de conservación, porque son zonas sujetas a inundación y generalmente no son aptas para el desarrollo de actividades productivas, sin embargo, se pudo observar que las actividad agrícolas, orillan a procesos (presumiblemente la «roza», tal vez la «tumba», y la «quema») que favorecen los renuevos de la vegetación secundaria, inicialmente $C$. jamaicense, lo que a su vez puede estar asociado con actividades de cacería menor de autoconsumo. De esta manera, la vegetación se encuentra en un proceso continuo de regeneración y en alguna medida se fomenta la distribución de una vegetación de herbáceas y arbustivas, lo que a su vez limita la distribución de una mayor diversidad de especies.

\section{Conclusión}

Las diferencias encontradas en los cuerpos de agua observados en el sitio de estudio (El Creek, Laguna Guerrero y Laguna Chile Verde), nos permite saber que existe a la fecha un grado de conservación ecológica bastante aceptable y por lo tanto, es posible plantear programas de protección a esos ambientes, acordes con los planes de desarrollo sostenible de estas comunidades. En el caso de El Creek, la fortaleza se pueden enfocar básicamente en potenciar la diversidad biológica de las plantas acuáticas estrictas, las plantas semiacuáticas, la vegetación de galería y los manglares, en «tours» de recorridos en lancha, en kayaks, o caminatas a lo largo de la ribera. En lo que concierne a las otras lagunas, el potencial más fuerte radica en el uso racional y sustentable que se le puede dar a los cuerpos de agua, también en recorridos en lancha o tramos cortos para la natación y el esparcimiento (específicamente en la parte más cercana al poblado), en los petenes, los manglares y la zona riparia, y los recorridos en caminatas en la zona continental. El conocimiento ecológico de estos ecosistemas estratégico, aunado a eficaces medidas de mitigación de impactos y conservación hacen factible que el turismo de aventura sea una actividad económicamente factible en el área de estudio.

\section{Agradecimientos}

Al Dr. Celestino Chargoy Zamora de la Universidad Autónoma Chapingo, quien financió parte de este estudio; al Dr. Germán Carnevali Fernández Concha del Centro de Investigación Científica de Yucatán, que me auxilió en la identificación de especies, y al 
Lic. Luis Xavier Román Cálix del Congreso del Estado de Quintana Roo, que me acompañó y ayudó en los viajes de campo.

\section{Literatura citada}

Allan JD, Flecker AS. 1993. Biodiversity conservation in running waters. BioScience 43: 32-43.

Beddows P, Blanchon P, Escobar E, Torres-Talamante O. 2003. Los cenotes de la península de Yucatán. pp. 32-5. En línea. (Acceso 23 de junio de 2013) URL en: http:// www.seduma.yucatan.gob.mx/cenotes-grutas/ documentos/cenotes-peninsula.pdf)

Cabrera CE, Souza M, Téllez O. 1982. Imágenes de la flora quintanarroense. Quintana Roo: Centro de Investigaciones de Quintana Roo (CIQRO). 224 pp.

Cálix de Dios H, Novelo AR, Koch SD. 1996. Vegetación de zonas inundables en Tabasco, México. Univers Cien. 12 (24): 28-40.

CDI. 2009. Parque ecoturístico Uchbenkah. (En línea). Comisión Nacional Para el Desarrollo de los Pueblos Indígenas (CDI). (Acceso 3 de octubre de 2012). Disponible en:http:/ /www.cdi.gob.mx/ecoturismo/quintanaroo_uch benkah.html

Cortina CB, Silva S. 2000. Visiones sobre el futuro de los recursos naturales de las comunidades de Laguna Guerrero y Raudales, Quintana Roo. Una aproximación antropológica. (En línea). (Acceso: 5 de octubre de 2012: en Quintana Roo: Universidad de Quintana Roo. 33 pp. URL disponible en: http://www3.uqroo.mx/sigc/Guia\%20final/ 59/CAP\%20Turismo.pdf

Challenger A, Soberón J. 2008. Los ecosistemas terrestres. En: Capital natural de México. Vol. I. Conocimiento actual de la biodiversidad. México: Conabio. pp. 87-108.

Díaz W, Rosales J. 2006. Análisis florístico y descripción de la vegetación inundable de várzeas orinoquenses en el Bajo Río Orinoco, Venezuela. Acta Bot Venez. 29 (1): 39-68.

Durán GR. 1995. Diversidad floristica de los petenes de Campeche. Acta Bot Mex. 31: 73-84.

Enquist BJ, Sullivan JJ. 2001. Vegetative key and descriptions of tree species of the tropical dry forests of upland Sector Santa Rosa, Área de Conservación Guanacaste, Costa Rica. 68 p. (En línea). Acceso 4 de noviembre de 2013, en: http://www.acguanacaste.ac.cr/paginas_especie/ plantae_online/EnquistSullivanTreeKey.pdf

Flores G, Durán GR, Ortiz DJ. 2011. Comunidades vegetales terrestres. En: Durán GR, Méndez M (eds.). Biodiversidad y desarrollo humano en Yucatán. pp: 125-9. Mérida: CICY, PNUD, CONABIO.

Foroughbakhch PR, Céspedes CAE, Alvarado VMA, Núñez GA, Badii MH. 2004. Aspectos ecológicos de los manglares y su potencial como fitorremediadores en el Golfo de México. Monterrey: Universidad Autónoma de Nuevo León. (En línea) (Acceso 4 de febrero de 2013). URL disponible en: http://eprints.uanl.mx/599/1/ art_manglares.pdf
Fueyo L. 2008. Manglares de México. CONABIO. 38 p. (En línea). 2008. (Acceso 20 de enero de 2013). URL disponible en: http://www.conabio.gob.mx/conocimiento/ manglares/doctos/manglaresMexico.pdf

Grantley J, McPherson F, Petroeschevsky A, Stevens M, Van Oosterhout, E. 2009. Recognising water weeds. Plant identification guide. Aquatic Weeds Early Detection Project. Industry \& Investment NSW, Grafton Primary. Industries Institute, PMB 2, Grafton, The State of New South Wales Industry \& Investment. NSW. Reino Unido. 80 p. (En línea). (Acceso 4 de noviembre de 2010). URL disponible en: http://www.dpi.nsw.gov.au/_data/assets/ pdf_file/0007/329308/041209-DPI-RWW-PLANTGUIDE.pdf)

Groves CR, Jensen DB, Valutis LL, Redford KH, Shaffer ML, Scott JM. 2002. Planning for biodiversity conservation: putting conservation science into practice. BioScience. 52: 499-512.

Gutiérrez BC, Ortiz DJ, Flores GJ, Zamora-Crescencio P, Domínguez C, Villegas P. 2011. Estructura y composición florística de la selva mediana subcaducifolia de NohalalSudzal Chico, Tekax, Yucatán, México. Forest Veracruz. 13 (1): 7-14.

Herrera SJ, Ceballos E. 1998. Manglares: ecosistemas valiosos. CONABIO Biodiversitas. 1: 1-10.

Lembi C. 2009. Aquatic plant management. Identifying and managing aquatic vegetation. Formerly Purdue University Extension; publication WS-21-WE. (En línea) (Acceso 3 de noviembre de 2013). URL disponible en: http:// www.extension.purdue.edu/extmedia/APM/ APM_3_W.pdf

Leopold AS. 1950. Vegetation zones of Mexico. Ecology. 31 (4): 507-18.

López PJA, Vázquez RVM, Gómez ALR, Priego SAG. 2010. Humedales. En: Florescano E, Ortiz EJ. (Coord.). Atlas del patrimonio natural, histórico y cultural de Veracruz. pp. 227-48. Gobierno del Estado de Veracruz: Comisión del Estado de Veracruz para la Conmemoración de la Independencia Nacional y la Revolución Mexicana: Universidad Veracruzana, México.

Miranda F. 1959. La vegetación de la Península de Yucatán. En: Los recursos naturales del Sureste y su aprovechamiento, estudios particulares. México, DF: IMRNAR. pp. 21571.

Miranda F, Hernández XE. 1963. Los tipos de vegetación de México y su clasificación. Bol Soc Bot Mex. 28: 28-79.

Mora-Olivo A, Villaseñor JL, Martínez M. 2013. Las plantas vasculares acuáticas estrictas y su conservación en México. Acta Bot Mex. 103: 27-63.

Maruti KV. 2009. Agro-tourism: scope and opportunities for the farmers in maharashtra. indiastat.com pp: 1-11. (En línea). (Acceso 24 de noviembre de 2012). URL disponible en: http://www.researchgate.net/publication/ 228289508_Agro-Tourism_Scope_and_Opportunities_ for_the_Farmers_in_Maharashtra

Murrell, ZE. 2010. Vascular plant taxonomy. Kendall Hunt Pub Co. USA. 632 p.

Parker R. 2005. Aquatic vegetation management and control. 
(En línea). (Acceso 18 de septiembre de 2013). URL disponible en: http://cru.cahe.wsu.edu/CEPublications/ PNW0224/PNW0224.pdf

Rico-Gray V. 1982. Estudio de la vegetación de zonas costeras inundables del noroeste del estado de Campeche, México. Biotica. 7 (2): 171-90.Pennington TD, Sarukhan J. 1998. Árboles tropicales de México. Manual para la identificación de las principales especies. $2^{\mathrm{a}}$ ed. México, DF: Universidad Nacional Autónoma de México-Fondo de Cultura Económica. 523 pp.

Ramos VLJ, Novelo RA. 1993. Vegetación y flora acuáticas de la laguna de Yuriria, Guanajuato, México. Acta Bot Mex. 25: 6 -79.

Rizzo D, Boser, SM. 2009. A field guide to common aquatic plants of Pennsylvania. Ag Communications and Marketing. College of Agricultural Sciences. The Pennsylvania State University, USA. 108 pp. (En línea). (Acceso 4 de noviembre de 2010). URL disponible en: http://pubs.cas.psu.edu/FreePubs/pdfs/agrs110.pdf)

Rodríguez MT, Vázquez-Lule A. 2006. Los manglares, conocimiento e importancia. CONABIO. (En línea) 2006. (Acceso 4 de enero de 2012 en: http://www.biodiversidad. gob.mx/ecosistemas/manglares/pdf/manglares_general.pdf www.conabio.gob.mx/conocimiento/manglares/doctos/ manglares.html).

Rzedowski J. 1978. Vegetación de México. México, DF: Limusa. 375 pp.

Rzedowski J. 1998. Diversidad y orígenes de la flora fanerogámica de México. En: Ramamoorthy TP, Bye R, Lot A, Fa J (eds.) Diversidad biológica de México: orígenes y distribución. pp: 129-45. México, DF: Instituto de Biología, UNAM.

Rzedowski J. 2006. Vegetación de México. Edición digital, Comisión Nacional para el Conocimiento y Uso de la Biodiversidad (CONABIO). México. (En línea) (Acceso 20 de abril de 2013). URL disponible en: http:// www.biodiversidad.gob.mx/publicaciones/librosDig/pdf/ VegetacionMx_Cont.pdf

Saunders DL, Meeuwig JJ, Vincent ACJ. 2002. Freshwater protected areas: strategies for conservation. Conservat Biol. 16: 30-41.

Sánchez GD, Batres GJ. 2007. Retos de la planeación turística en la conservación de las lagunas urbanas de gradadas de
México. El caso de Tampico. Cuad Geograf. 41 (2): 24152.

SEMARNAT. 2011. Chetumal, Quintana Roo. 13 pp. (En línea). (Acceso 2 de abril de 2014). URL disponible en: http:// digaohm.semar.gob.mx/cuestionarios/cnarioChetumal.pdf

Valdéz HM, Islebe GA. 2012. Tipos de vegetación en Quintana Roo. En: C. Pozo (ed.). Riqueza biológica de Quintana Roo. Un análisis para su conservación. Tomo 2. pp. 326. México, DF: El Colegio de la Frontera Sur (Ecosur), Comisión Nacional para el Conocimiento y Uso de la Biodiversidad (CONABIO). Gobierno del Estado de Quintana Roo y Programa de Pequeñas Donaciones.

Vester HFM, Calmé S. 2003. Los ecosistemas terrestres de la Península de Yucatán: estado actual de los paisajes, vegetación, flora y fauna. pp. 159-73. En: Naturaleza y sociedad en el área maya pasado presente y futuro. Colunga-García Marín P, Larqué Saavedra A. Mérida: AMC y CICY.

VLMP. 2001. A key to common native maine aquatic plant species adapted. Maine Center for Invasive Aquatic Plants (MCIAP). Maine Center for Invasive Aquatic Plants. 20 pp. (En línea). (Acceso 4 de noviembre de 2013). En: http://www.mainevolunteerlakemonitors.org/mciap/ MaineKeyToCommonNativeAPS.pdf

Ward JV. 1988. Riverine landscapes: biodiversity patterns, disturbance regimes and aquatic conservation. Biol Conserv. 83: 269-78.

Waters E, Kimberley M. 2007. Guide to tropical plant families and genera. To assist students on the University of Manchester Biology Field Course to the Payamino Territory in Ecuador. Royal Botanic Gardens, Kew. 48 pp. (En línea). (Acceso 4 de noviembre de 2013) URL disponible en: http://www.payaminoproject.org.uk/plantguide.pdf

Zaldívar JA, Herrera SJ, Teutli HC, Hernández SR, Caamal SJ. 2011. Manglares. En: R. Durán G, Méndez M (eds.). Biodiversidad y desarrollo humano en Yucatán. pp. 1389. México, DF: CICY, PNUD, CONABIO.

Zur Heide F. 2012. Feasibility study for a lake tana biosphere reserve, Ethiopia. Federal Agency for Nature Conservation; Michael Succow Foundation for the protection of Nature; Federal Ministry for the Environment, Nature Conservation and Nuclear Safety. (En línea). (Acceso 20 de noviembre de 2013). URL disponible en: http://www.bfn.de/0502_skripten.html 